\title{
A VIDA DO SOL NA TERRA: DESENVOLVIMENTO DE PERSONAGENS A PARTIR DE ELEMENTOS DA CULTURA GUARANI-MBYA
}

Bruno Müller da Silva

Universidade Estadual Paulista

brn.muller@gmail.com

Prof. Dr. Claudio Roberto y Goya

Universidade Estadual Paulista

goya@faac.unesp.br

Resumo: Este artigo trata da pesquisa e desenvolvimento de parte de um trabalho de conclusão de curso em Design de Produto, no qual foram projetados figurinos, adereços e demais paramentos teatrais inspirados no livro bilíngue "A vida do sol na terra - Kuaray'i ywy rupáre oiko'i ague", que relata a origem do sol e da lua segundo a cosmologia dos Guarani-Mbya, povo indígena que vive num grande território entre Paraguai, Argentina, Sul e Sudeste do Brasil. Os personagens foram embasados em conceitos antropológicos e étnicos desse povo, traduzidos em ilustrações que foram desenvolvidas primando por princípios da etnografia, de forma a estabelecer conexões com a cultura Mbya.

Palavras-chave: Teatro, Figurino, Cultura Indígena, Guarani, Mbya.

\begin{abstract}
This paper describes the research and development of part of a larger work, a final project in the undergraduate course of Product Design, in which we developed costumes, props and several other theatrical elements inspired on the bilingual book " $A$ vida do sol na terra - Kuaray'i ywy rupáre oiko'i ague", which tells the story of the birth of the Sun and the Moon according to the Guarani-Mbya cosmology. The Mbya are an indigenous people that lives upon a great territory between Paraguay, Argentina, South and South-eastern Brazil. The characters were based on anthropological and ethnic concepts of this people, translated on illustrations that were developed under a methodology ruled by ethnographic principles.
\end{abstract}

Keywords: Theatre, Costume, Indigenous Culture, Guarani, Mbya. 


\section{INTRODUÇÃO}

Os Guarani estão entre os povos indígenas mais presentes na América do Sul. No entanto, por suas características de mobilidade, redes de parentesco e vastos territórios, além do acesso difícil ou a aversão a recenseadores, há uma imensa dificuldade em quantificá-los. Segundo dados do Censo Demográfico de 2010, a população indígena brasileira corresponde a cerca de 817.963 pessoas, vivendo entre áreas urbanas e rurais. Dessas, aproximadamente 51.000 são da etnia Guarani, dividida entre os subgrupos Kaiowá (31.000), Ñandevá (13.000) e Mbya (7.000). Estes últimos estão espalhados entre o Espírito Santo, Rio de Janeiro, São Paulo, Paraná, Santa Catarina e Rio Grande do Sul, com grupos menores em Tocantins e Pará. Além da presença no Brasil, os Mbya também são encontrados na província de Misiones, na Argentina (5.500) e no Paraguai (14.887) (LADEIRA, 2009).

Publicado em 2003, o livro bilíngue "A vida do sol na terra - Kuaray'i ywy rupáre oiko'i ague", de Verá Kanguá e Papa Mirĩ Poty, traz em português e guarani a narrativa de uma das muitas aventuras dos irmãos Kuaray e Jaxy, dois meninos que viriam a se tornar o Sol e a Lua quando deixassem este mundo.

Nessa história, diversos personagens recorrentes da cosmogonia Guarani-Mbya são apresentados, como Nhanderu, o deus supremo, criador do mundo; Xariã, seu irmão mais velho, que corrompe e imita toda criação; Nhanderuxy, a mãe do sol, a guarani pela qual Nhanderu se apaixonou no começo das coisas; e os irmãos Kuaray, o Sol, e Jaxy, a Lua, tidos pelos Guarani como exemplos a serem seguidos, sendo as divindades mais próximas da humanidade, aquelas nas quais os homens devem se espelhar para, quando chegada a hora, transcender o mundo terreno e partir para Yvy Marã E'ỹ, a terra imperecível, morada dos deuses e o lugar onde os costumes antigos ainda são mantidos, sem a interferência do homem branco.

O objetivo deste trabalho é usar o design, por meio da linguagem teatral, para contar a história do livro, adaptando-a para a arte dramática por meio do figurino, adereços, maquiagem, bonecos e demais elementos que possam ser criados para amparar o espetáculo narrativo. Não é do escopo deste projeto o desenvolvimento de roteiro e texto, mas sim de todos os artefatos e componentes visuais necessários para a possível realização de uma peça de teatro que celebre uma das muitas narrativas tradicionais originárias da nossa terra. A força motriz desse projeto é tornar visível uma cultura que é atirada às margens da sociedade brasileira, em uma época de grandes conflitos em nome da demarcação das terras originais desses povos, e mostrar como a interação entre design e antropologia pode colaborar nesse sentido.

Como abordagem projetual, decidimos fazer com que as decisões metodológicas fossem embasadas firmemente em pesquisas antropológicas e etnográficas acerca dos Guarani-Mbya, de modo que a sua cultura seja fielmente visível, além de enriquecer o campo do design ao partir de uma referencial nãoconvencional para o desenvolvimento de um projeto de produto.

Neste artigo, relatamos a pesquisa e o desenvolvimento dos principais personagens do livro, descrevendo os conceitos iniciais que permanecem como base projetual dos demais elementos cênicos - adereços, bonecos, figuração, entre outros e para efetiva produção de figurino, máscaras e maquiagem dos protagonistas. 


\section{DESENVOLVIMENTO}

\subsection{Enredo}

Resumidamente, o enredo do livro trata de quando Nhanderu Papa Tenonde, o criador do mundo, desce à terra e se apaixona por uma mortal, Nhanderuxy, que engravida. A divindade volta ao mundo celeste, mas a mortal recusa o convite para ir junto, e fica sozinha no mundo, andando pela mata guiada pelo filho divino, Kuaray (o Sol), ainda na barriga. Enganada por onças, a mulher é morta, mas seu bebê sobrevive, e é criado pela Avó Primeira-Onça, sem saber que ela, junto dos netos, foi a responsável pelo assassinato da sua mãe.

Um dia, Kuaray sai caçando pela mata e, usando seus poderes, cria para si seu irmão mais novo, Jaxy (a Lua). Os dois passam por muitos percalços juntos até descobrirem que as onças mataram sua mãe, e voltam ao ninho delas com um plano para se vingarem. Levam-nas a um lago, com uma ponte improvisada entre a margem e uma ilha, que fica no centro, com a promessa de frutos maravilhosos. Enquanto atravessam a ponte, os irmãos a viram, e as onças caem na água, transformando-se nos animais aquáticos. Jaxy fica preso na terra, e Kuaray na ilha fica o ensinando à distância, até que o caçula consegue ir para a ilha. Andando por lá, os dois encontramse com Xariã, o astuto irmão mais velho de Nhanderu, que devora Jaxy (causando um eclipse). Kuaray foge e consegue ressuscitar o irmão, e ambos seguem para a morada celeste, na qual o pai os aguardava.

\subsection{Delimitação de Personagens}

Descrevemos neste artigo o processo de desenvolvimento de cinco personagens originados do texto, a quem chamamos conjuntamente de "ancestrais". Por ancestrais entenda-se as pessoas da história que têm forma humana, mesmo que sejam divindades: Nhanderu, Nhanderuxy, Kuaray, Jaxy e Xariã ${ }^{1}$.

Nhanderu, também chamado Nhanderu Papa Tenonde, é a divindade suprema da cosmologia Guarani-Mbya, criador do mundo e de tudo o que nele existe. Existem inúmeros outros deuses que cuidam da criação (como Tupã, por exemplo) mas que não entram nesta história. Nhanderuxy é a mulher mortal escolhida por Nhanderu para ser mãe do seu filho, Kuaray, que um dia viria a se tornar o Sol; quando ela morre, é ressuscitada pelo filho, na forma de um animal, dando origem à paca.

Em suas andanças, Kuaray cria, a partir de uma folha de leiteiro, o seu irmão Jaxy, que um dia viria a ser a Lua. Xariã, também chamado de Anhã, aparece por último na história. É considerado irmão mais velho de Nhanderu, e conhecido por corromper a criação do irmão mais novo, tentando sempre imitá-lo, mas nunca conseguindo superá-lo.

\subsection{Unidade, Dualidade, Tríade}

Um dos conceitos fundamentais elencados para o desenvolvimento dos personagens parte da crença dos Mbya numa série de transformações, realizadas pelas divindades, e que afetam tanto sua própria existência (como deuses) quanto a criação das pessoas, animais e todos os demais seres vivos na terra.

\footnotetext{
${ }^{1}$ Considerando o dialeto Mbya do Guarani, esses nomes são, grosso modo, pronunciados como nhanderú, nhanderutchí, kuaraí, djatchí e tsariã, respectivamente (DOOLEY, 2013).
} 
São múltiplos os seres que povoam as plataformas celestes, criados como desdobramentos um dos outros. A unidade sempre encerra uma dualidade, e a dualidade sempre contém uma tríade, que se desdobra em outra dualidade, sucessivamente, sem cessar. O Dois povoa o Um, o Três povoa o Dois e o Múltiplo povoa o Três.

Inicia-se pelo desdobramento de Nhanderu Tenonde no demiurgo Nhamandu (Sol), um dos Pais das Almas, mas ele também se desdobra em Karai Ru Ete, Jakaira Ru Ete, Tupã Ru Ete, da mesma maneira como a Anta desdobra-se em Capivara, que se [...] desdobra em Cotia, que se desdobra em Preá. "De um ser podem surgir várias nações", dizia o karai [do filme] Bicicletas de Nhanderu. (PIERRI, 2013, p.103).

"Nhamandu" é como Kuaray é chamado em seu aspecto de divindade na linguagem sagrada, fora das suas histórias como pessoa. A coletânea de mitos dos Mbya realizada por León Cadogan (1959) aponta que Nhanderu tinha uma grande luz em seu peito, e que dessa luz nasceu o Sol, ou seja, Kuaray era parte do seu pai, ao mesmo tempo que tornava-se um ser independente. Esse motivo - o da unidade que encerra uma dualidade - é a base para a construção de todos os personagens neste projeto. Sendo assim, antes de desenvolver cada um deles independentemente, pensamos em tríades e pares, reunidos de acordo com relações específicas, ditadas principalmente pela mitologia mbya e, em alguns pontos, decidida por elementos em comum percebidos ao longo da pesquisa.

Os personagens ancestrais, por representarem os deuses e sua ligação com os guarani, são desenvolvidos levando em consideração as transformações divinas e o conceito de unidade, dualidade e tríade, ou seja, agrupados primeiro em trios, sendo o personagem central o ponto de ligação entre as extremidades divergentes, representando o equilíbrio entre as mesmas. Foram elencadas características comuns a estes personagens, em cada tríade, valorizando aspectos que poderiam ser traduzidos por meio de signos visuais facilmente reconhecíveis, utilizando especialmente os grafismos da cestaria Mbya como elemento de destaque (Quadro 1).

Quadro 1 - Características das Tríades de Ancestrais

\begin{tabular}{|c|c|c|c|}
\hline & I & II & III \\
& Xariã-Nhanderu-Kuaray & Nhanderu-Kuaray-Jaxy & Kuaray-Jaxy-Nhanderuxy \\
\hline Relação & Demiurgos & Divindades Celestes & Família \\
\hline Grafismo & Ipara kuruxu'i & Ipara kora joa & Ipara kora \\
\hline Cor & Preto & Branco & Vermelho \\
\hline
\end{tabular}

Fonte: elaborado pelo autor, com base na pesquisa realizada.

Na tríade I: Xariã-Nhanderu-Kuaray, temos três demiurgos, isto é, divindades relacionadas à criação do mundo e das coisas que nele existem. Baseados em Lorenzoni (2010, pp. 144-148), escolhemos o grafismo ipara kuruxu'i ("desenho em cruz pequena"), também chamado ipara kora guaxu ("desenho cercado grande"), como um dos elementos de ligação, visto que representa uma cruz, que para os guarani podem significar tanto uma divindade quanto os pilares nos quais o mundo se apoia (Figura 1). O preto foi escolhido como cor dessa tríade, visto que na cosmologia guarani os demiurgos surgem da noite primordial. 


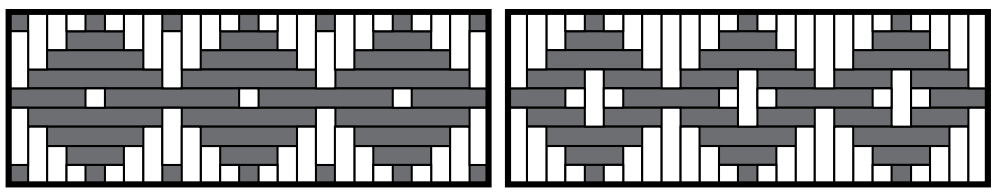

Figura 1 - Ipara kuruxu e ipara kuruxu'i.

Adaptado de Lorenzoni (2010, p. 148).

A segunda tríade, II: Nhanderu-Kuaray-Jaxy representa as principais divindades dos guarani, as que servem de exemplos a serem seguidos pelos Mbya. Para este trio, escolhemos o grafismo ipara kora joa ("desenho cercado contornado"), que é especialmente admirado por esse povo, tendo diversas aplicações e sendo bastante visto em manifestações contemporâneas (Figura 2). A cor de ligação da tríade é o branco, relacionado à luz.

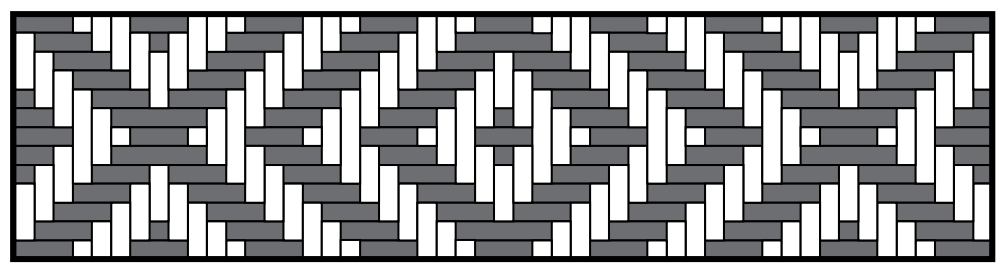

Figura 2 - Ipara kora joa.

Adaptado de Lorenzoni (2010, p. 147).

Por último, a tríade III: Kuaray-Jaxy-Nhanderuxy representa a família, os dois filhos divinos com a mãe humana. O grafismo ipara kora ("desenho cercado"), para os Mbya do Espírito Santo, a bifurcação desse signo representa a cobra cascavel, considerada invencível entre as demais cobras; sua aplicação como pintura corporal tem o sentido de guerreiro ou lutador, e os guarani utilizam esse símbolo para se identificarem como um povo batalhador (Figura 3). O vermelho, nessa tríade, representa tanto o sangue quanto as pinturas corporais, feitas com essa cor.
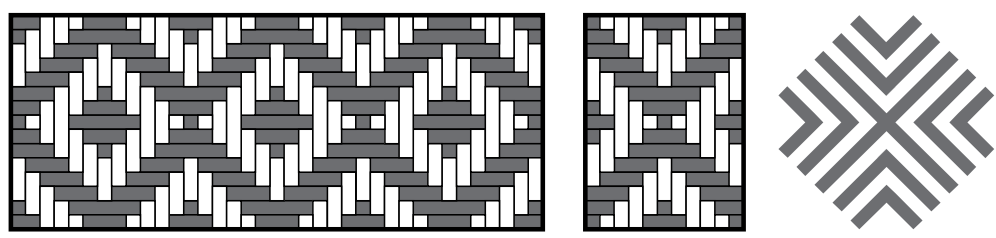

Figura 3 - Ipara kora, bifurcação e padrão de pintura.

Adaptado de Lorenzoni (2010, pp. 144-145).

O mesmo foi feito a seguir com pares de ancestrais (Quadro 2), até culminar no desenvolvimento individual, acumulando os dados de cada etapa até o desenho final de cada um dos personagens. A relação de dualidade é amparada pela continuidade entre cada par, conforme explica Lévi-Strauss comentando a mitologia ameríndia, na qual, em geral, os mitos

[...] representam a organização progressiva do mundo e da sociedade na forma de uma série de bipartições, mas sem que entre as partes resultantes em cada etapa surja jamais uma verdadeira igualdade. Desse desequilíbrio dinâmico depende o bom funcionamento do sistema, que, sem isso, estaria 
constantemente ameaçado de cair num estado de inércia. O que tais mitos proclamam implicitamente é que os polos entre os quais se organizam os fenômenos naturais e a vida em sociedade - céu e terra, fogo e água, alto e baixo, perto e longe, índios e não-índios, conterrâneos e estrangeiros etc. nunca poderão ser gêmeos (LÉVI-STRAUSS, 1993 [1991] apud PIERRI, 2013, p. 44).

É importante discorrer sobre a importância do conceito de diferença contínua nas dualidades apresentadas, ou seja, em vez de opostos, os componentes de cada par representam continuidade um no outro. Na história, Kuaray cria Jaxy a partir de uma folha de leiteiro; os dois são irmãos quase que idênticos, muitas vezes vistos erroneamente como gêmeos, mas um é o criador e o outro, o criado. A Lua é continuidade do Sol, mas é um ser completamente independente deste. É interessante levantar esse conceito para o trabalho em design pois ele também é útil para pensar a continuidade entre os Guarani e as divindades, a quem chamam de Nhanderyke'y Kuery ("nossos irmãos mais velhos"), ainda que os corpos dos Guarani sejam apenas imagens do corpo dos deuses, como tudo aquilo que é gerado no mundo terrestre (PIERRI, 2013, p. 47).

Quadro 2 - Características dos Pares de Ancestrais

\begin{tabular}{|c|c|c|c|c|} 
& $\begin{array}{c}\text { I } \\
\text { Xariã-Nhanderu }\end{array}$ & $\begin{array}{c}\text { II } \\
\text { Nhanderu-Kuaray }\end{array}$ & $\begin{array}{c}\text { III } \\
\text { Kuaray-Jaxy }\end{array}$ & $\begin{array}{c}\text { IV } \\
\text { Jaxy-Nhanderuxy }\end{array}$ \\
\hline Relação & Opostos & Líderes & Teko porã/tekoaxy & Humano-divino \\
\hline Objeto & Altar & Yvyra'i & Aparelhos & Petỹgua \\
\hline
\end{tabular}

Fonte: elaborado pelo autor, com base na pesquisa realizada.

Sendo assim, o par I: Xariã-Nhanderu representa, num primeiro momento, uma relação de oposição, visto que pela mitologia dos Mbya Nhanderu é aquele que cria, e Xariã é aquele que, tentando criar, deforma e corrompe, mas sem necessariamente representarem o bem e o mal primordial. De certa forma, representam uma paridade caos/ordem. O objeto escolhido para representar essas duas figuras é o altar característico presente nas casas de reza dos guarani, chamado amba vera (ZOCCOLI e CASTANHEIRA, 2012, p. 397) mas enquanto este é visto em posição normal nos paramentos de Nhanderu, é colocado invertido nos de Xariã (Figura 4).

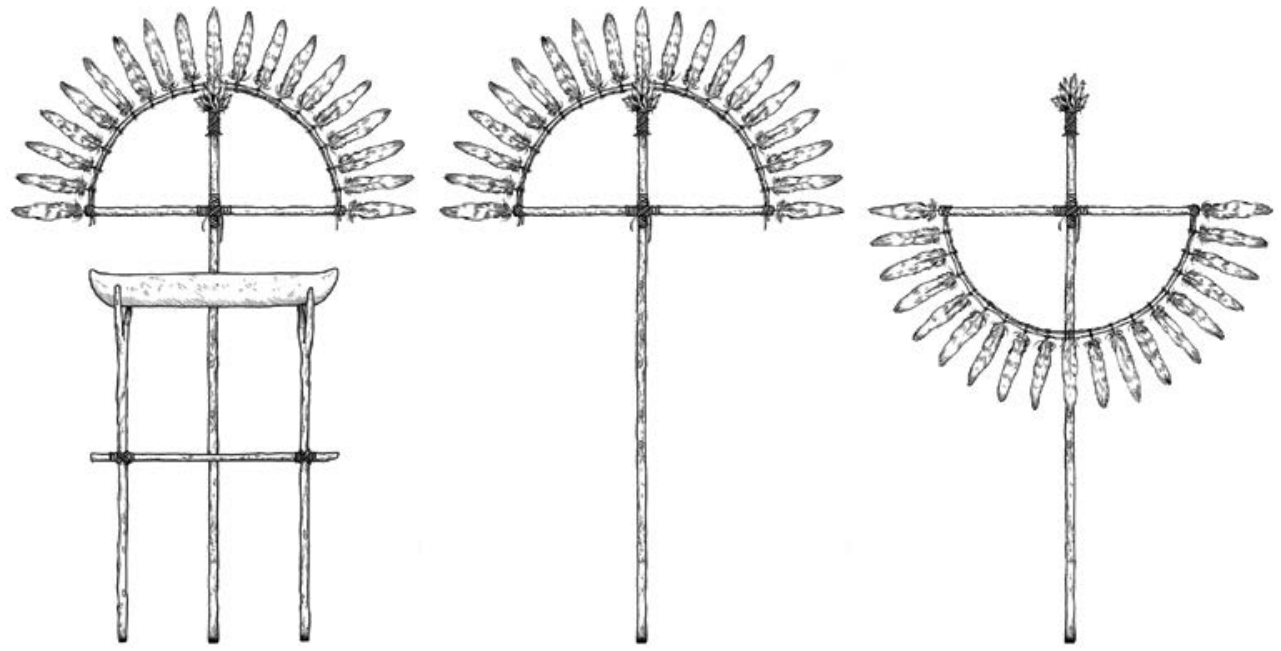

Figura 4 - À esquerda, desenho de um altar típico; ao centro: elemento escolhido para acompanhar Nhanderu; à direita: inversão feita para Xariã.

Elaborados pelo autor, com base na pesquisa realizada. 
O par II: Nhanderu-Kuaray representa, num primeiro momento, a relação pai e filho, mas mais do que isso, apresenta as principais figuras da religião Guarani-Mbya, os líderes espirituais desse povo. Por este motivo, o objeto compartilhado por ambos os personagens é a yvyra'i, uma vara-insígnia dupla de uso ritual, empunhada apenas pelos líderes religiosos de cada aldeia (Figura 5). Ela tem por si só o sentido de representar algo a ser seguido: Tupã, nhande yvyra'i: "Tupã, nosso guia" (BUGALLO, 2002, p. 39).

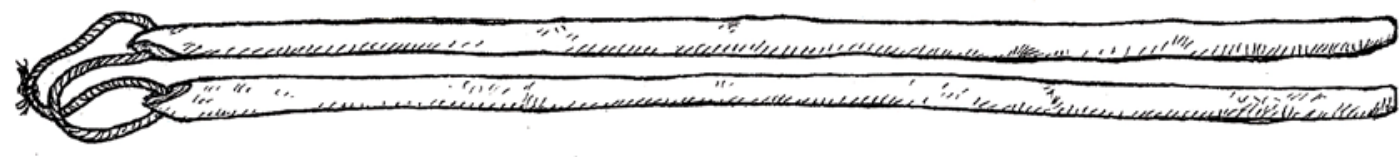

Figura 5 - Yvyra'i, a vara-insígnia.

Elaborado pelo autor, com base na pesquisa realizada.

Já o par III: Kuaray-Jaxy representa um dos conceitos mais fundamentais da cosmologia Mbya: a dicotomia entre teko porã e tekoaxy, os polos divino e mundano, respectivamente. Enquanto Kuaray traz consigo o modo divino de existir e ver o mundo, Jaxy representa o próprio povo guarani em relação ao seu irmão mais velho: alguém que está em um eterno aprendizado, que comete erros mas que almeja a divindade e a vida plena acima de tudo. Buscando elementos específicos deste par, nos deparamos com narrativas que falam que os irmãos carregam "aparelhos":

Ouvi algumas vezes de meus interlocutores guarani que o Sol é uma
divindade que carrega um aparelho, com o qual faz o seu trabalho de
iluminar e aquecer a plataforma terrestre. Um cacique me contava que esse
trabalho é o mais importante de todos, e que Kuaray é o maior exemplo de
todos de precisão. [...] Ele leva seu aparelho até o poente em linha reta, e
depois volta com o aparelho desligado. A lua também é um aparelho
carregado por Jaxy. Em outras versões da história [...], conta-se que
inicialmente Nhanderu Tenonde tentou designar Jaxy para iluminar o
mundo. Mas Jaxy era muito "rebelde", faltando no trabalho, e iluminando a
terra de maneira inconstante. Por isso, o trabalho foi repassado a Kuaray,
enquanto Jaxy ficou apenas com a função de iluminar a noite, atividade que
não demandava a mesma regularidade. (PIERRI, 2013, p. 48)

Os aparelhos dessas divindades, sendo artefatos mitológicos, não têm representação física, portanto foram criados de acordo com elementos e características atribuídos a Kuaray/Sol e Jaxy/Lua. A base de ambos é uma vara, similar a um cajado, cujo cimo emula a estrutura do altar de Nhanderu cercada por um jeguaka, um adorno de penas masculino. Antes de ser um jeguaka, no entanto, as formas são feitas para lembrar fogo, ideia vinda da palavra guarani para "estrela": jaxy-tata, ou seja, "fogo da lua"; presumindo que o astro tenha esse elemento, estendemos a mesma representação para o sol. Ainda seguindo o mito citado por Pierri (2013, supracitado), decidimos por fazer o círculo do sol completo, fechado, enquanto o da lua tem as pontas separadas, representando a irregularidade de Jaxy. A esses "aparelhos" demos os nomes de Kuaray Raku-a, o calor do sol, e Jaxy Rexakãa, o brilho da lua (Figura 6). O aparelho do Sol ainda tem pendurado em seu centro a vara- 
insígnia que Kuaray compartilha com Nhanderu (Figura 5), enquanto o da Lua tem o petỹgua que Jaxy divide simbolicamente com sua mãe (Figura 7).
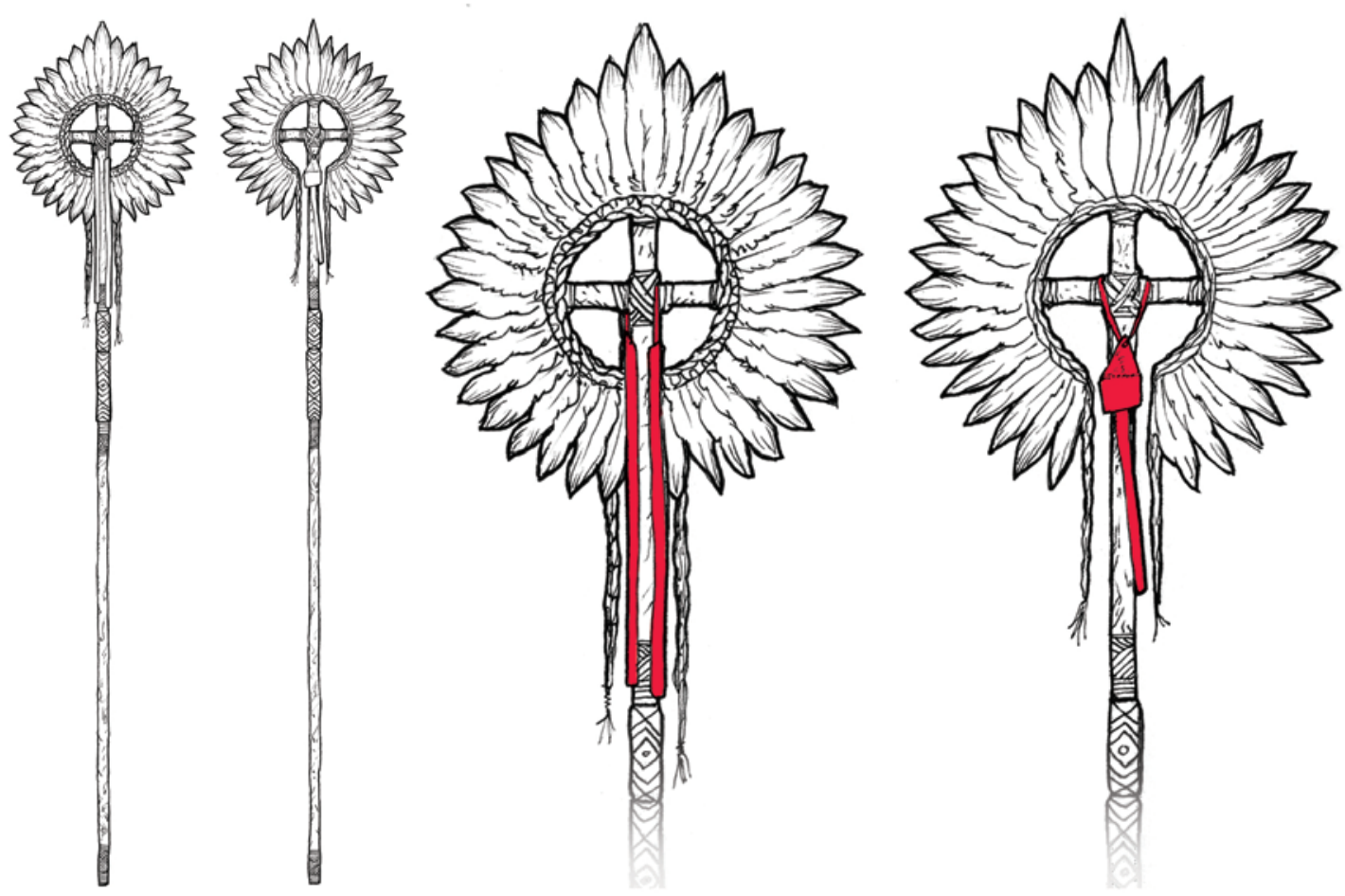

Figura 6 - Kuaray Raku-a e Jaxy Rexakãa, com seus objetos diferenciais destacados em vermelho. Elaborado pelo autor, com base na pesquisa realizada.

O último par, IV: Jaxy-Nhanderuxy representa uma relação direta entre uma guarani mortal e uma divindade imperecível, além da união da mãe com o filho, ainda que indiretamente, visto que Jaxy não veio de Nhanderuxy, sendo gerado por seu irmão a partir de uma árvore. Para refletir a transição entre divindade e humanidade, bem como a ponte entre masculino e feminino, o objeto escolhido para unir este par é o petỹgua, o cachimbo usado pelos xamãs para se conectar com os deuses, e que durante as cerimônias religiosas é utilizado por homens e mulheres.

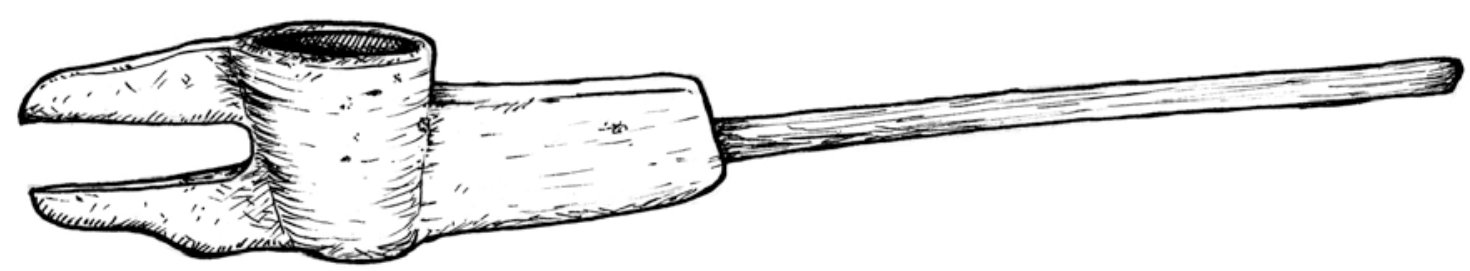

Figura 7 - Um tipo de petỹgua.

Elaborado pelo autor, com base na pesquisa realizada.

Após as características elencadas levando em consideração as tríades e os pares, partimos então para um processo de individuação desses personagens, considerando os elementos específicos de cada um deles.

Sendo assim, Nhanderu e Xariã (Figura 8), por serem divindades supremas e mais distantes do mundo terreno, usam máscaras, para representar este distanciamento e mistério em relação aos mortais. Nhanderu manifesta-se para 
Nhanderuxy, na história, na forma de uma coruja, e este também é considerado o primeiro animal a existir na noite originária, portanto, é esta a figura representada na máscara dessa divindade. Além da máscara, o jeguaka de Nhanderu tem cinco penas brancas em destaque, uma para cada ponto cardeal e mais uma para representar o centro do mundo, como é das crenças dos Guarani que existe um par de divindades em cada um desses locais. Logo, Nhanderu seria o ponto de ligação entre todas elas. Os colares e pulseiras usados por ele são os mesmos tradicionalmente elaborados pelos Mbya, usando sementes diversas, e as braçadeiras carregam adornos feitos de pequenas plumas.

$\mathrm{Na}$ história, Xariã não tem ligação com nenhum animal, portanto, para complementar sua figura, decidimos por meio do folclore brasileiro usar o mítico Anhangá, espírito que traz desgraça por onde passa, conhecido entre os Tupi, ancestrais distantes dos Guarani; pode manifestar-se como diversos animais diferentes, mas entre os mais conhecidos está sua assombração como veado branco, e foi este o escolhido para a máscara, fator também decidido graças ao nome alternativo de Xariã: Anhã (CASCUDO, 2012, p. 16). Seu jeguaka é semelhante em tamanho ao de Nhanderu, mas traz chifres exagerados, e seu cimo é quebrado, incompleto, demonstrando a imitação e a deformação dele perante o irmão mais novo; o mesmo é representado em seus colares e pulseiras, que tentam copiar os de Nhanderu, mas em vez de sementes, são feitos de pedras e outros objetos irregulares, imprecisos. As braçadeiras de Xariã, em vez de plumas, trazem penduradas crânios de pequenas aves.
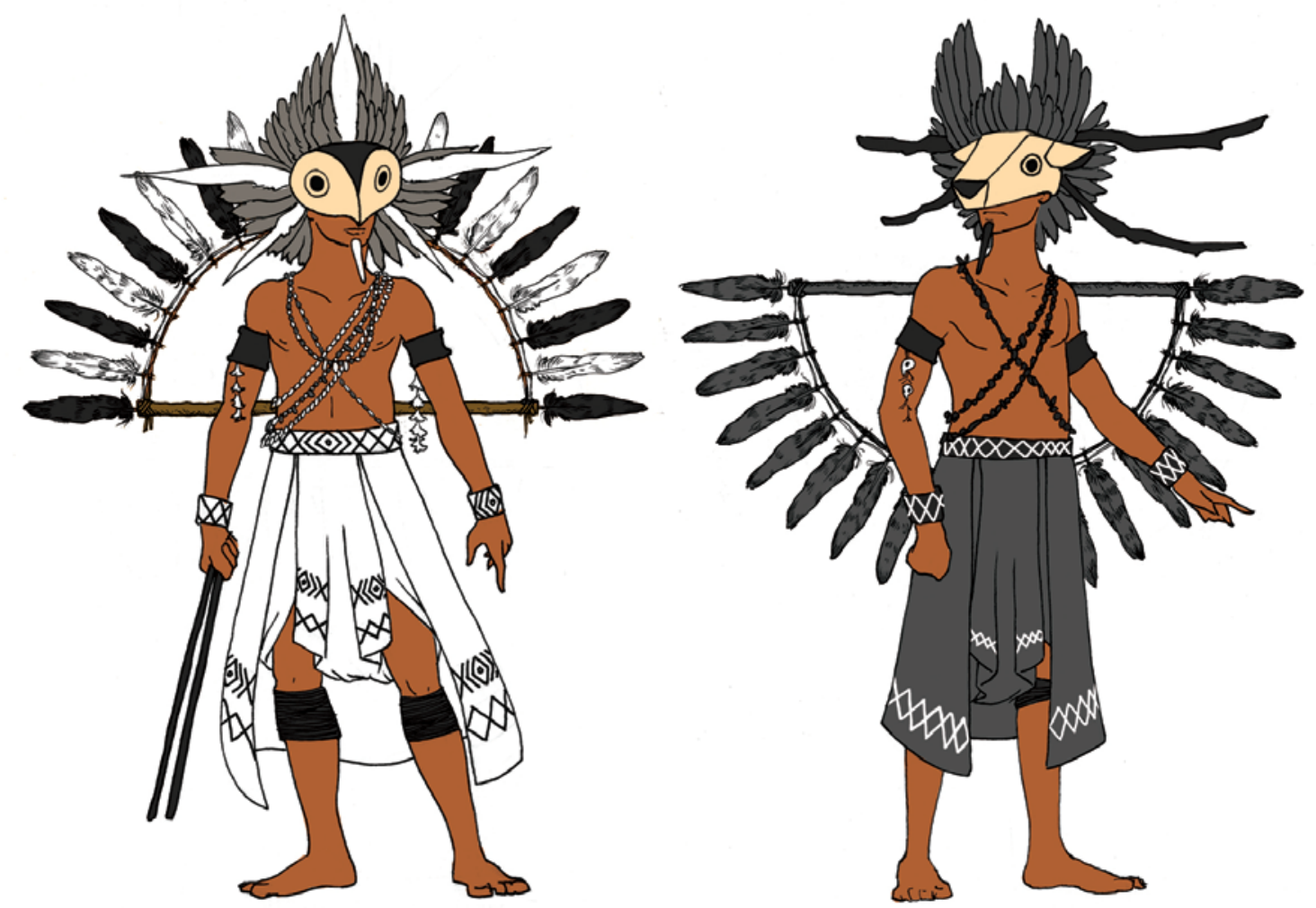

Figura 8 - Nhanderu e Xariã.

Elaborado pelo autor, com base na pesquisa realizada.

Kuaray e Jaxy (Figura 9) têm suas características individuais representadas principalmente nos "aparelhos" que carregam, e como são personagens quase gêmeos, seus figurinos são muito parecidos, com alguns ajustes de detalhes que os diferenciam. Kuaray tem características de três tríades distintas, e por isso tem mais 
detalhes em seu vestuário, exibindo três cores e três diferentes tipos de grafismos. Já Jaxy é feito todo baseado no irmão mais velho, mas apresentando características de imitação/criação, dado o fato que foi o menino sol que o criou. Levando em consideração seu nascimento, o jeguaka de Jaxy não é feito de penas, e sim de folhas de leiteiro (Sapium longifolium), a árvore da qual foi gerado.

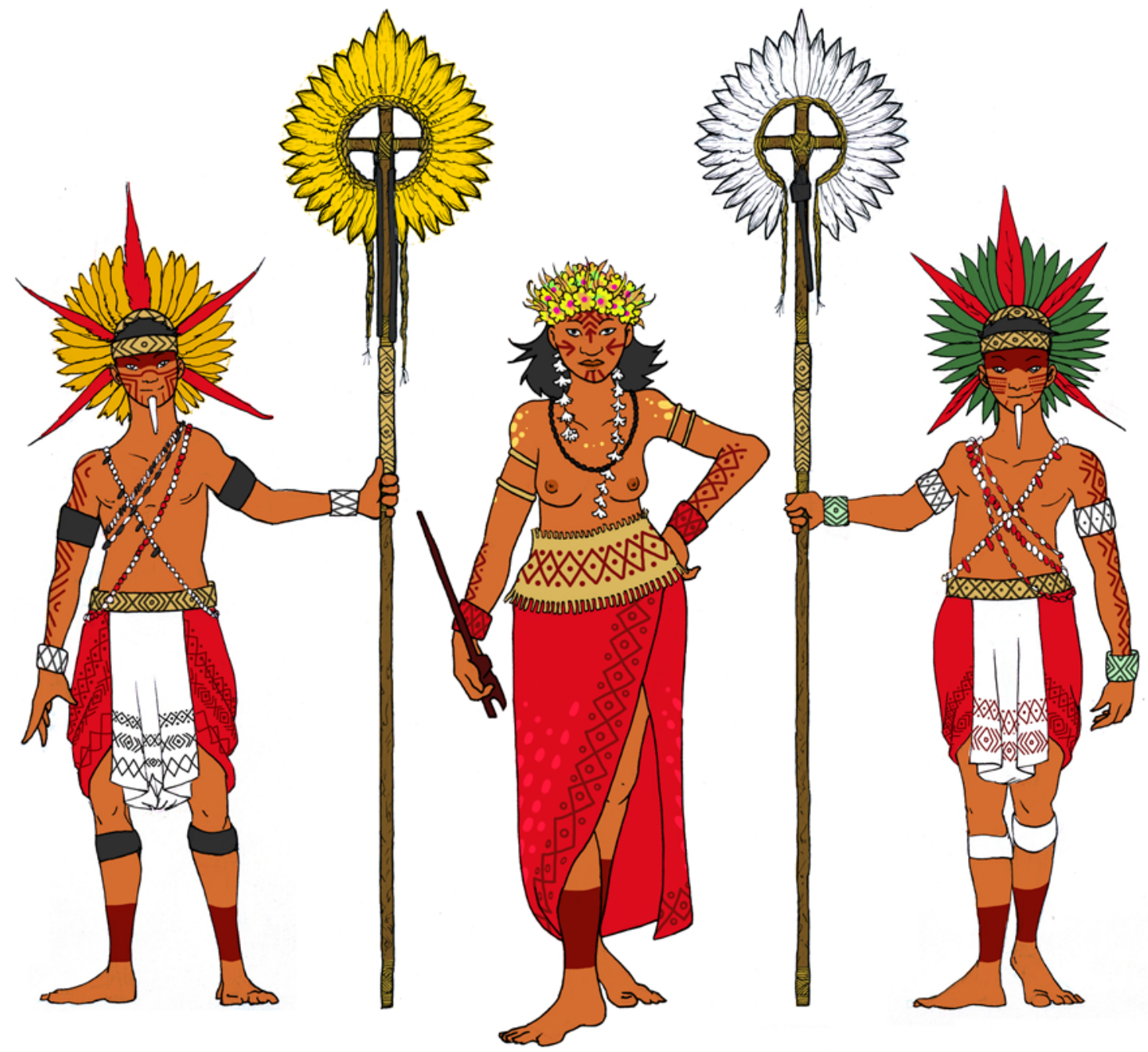

Figura 9 - Kuaray, Nhanderuxy e Jaxy.

Elaborado pelo autor, com base na pesquisa realizada.

Nhanderuxy, por ser a única mortal da história, é representada segundo o mito de criação dos seres humanos, que diz que Nhanderu criou o homem a partir de um arco, e a mulher a partir de um ajaka, um cesto tradicional. Este objeto é representado na cintura da personagem, adornado pelo trançado ipara kora que ela compartilha com os dois filhos. Além disso, traz em sua cabeça o jaxuka, touca ou cocar de flores considerado o emblema da feminilidade (CADOGAN, 1959). Incluindo elementos específicos do livro, levamos em consideração o fato de que, após a morte de Nhanderuxy, Kuaray a faz renascer em forma de paca (Cuniculus paca); isto é apontado já em seu figurino como humana, por meio das manchas mais claras em sua saia, costas, ombros e colo, imitando o padrão da pelagem desse animal.

\section{CONCLUSÃO}


Sendo este trabalho apenas parte de algo maior, em vez de uma conclusão definitiva fazemos aqui apenas considerações finais sobre todo o processo de desenvolvimento, visto que as bases aqui erigidas servem de suporte para outras áreas do mesmo projeto. Inicialmente, é importante ressaltar a grande dificuldade de se encontrar documentação de referências visuais em relação aos povos indígenas brasileiros, em especial os Mbya. Ainda que os Guarani sejam uma das nações originárias mais conhecidas e estudadas por antropólogos, etnólogos e diversos outros estudiosos das ciências sociais, é inexpressiva a presença de pesquisadores das áreas de arte e design no que se refere a investigar, documentar, divulgar e promover aspectos culturais desses povos, sobretudo no que se refere aos seus processos de criação, materiais e métodos de construção, além de um registro formal de seu artesanato, notadamente dos seus grafismos em cestaria e pintura corporal, tão conhecidos como patrimônio cultural latino-americano entre inúmeros povos originários.

Portanto, praticamente toda a documentação levantada para a criação visual dessas figuras partiu de dissertações do campo da antropologia, por meio de poucas fotografias e desenhos que representassem elementos de grande importância para o trabalho, especialmente no que se refere à indumentária tradicional dos Guarani, fator agravado pelo fato de hoje esse povo ser majoritariamente urbano, e por culpa muitas vezes da falta de políticas públicas direcionadas à preservação da cultura ancestral, muito se perde sem sequer deixar um registro histórico.

Deste modo, buscamos com esse trabalho e seus desdobramentos contribuir, por meio do design, com a representatividade dos povos originários em nosso meio, e acreditamos estar dando passos, pequenos mas importantes, em direção a uma maior aceitação e celebração das tantas nações que existem em nosso território.

\section{REFERÊNCIAS}

BAXTER, M. Projeto de produto: guia prático para o design de novos produtos. 3a. ed. São Paulo: Blucher, 2011.

BUGALLO, R. P. El iwyra'í: relicto sonoro de la vara-insignia entre los Mbya. Relaciones de la Sociedad Argentina de Antropología, Buenos Aires, 2002.

CADOGAN, L. Ayvu Rapyta: textos míticos de los Mbyá-Guaraní del Guairá. Revista de Antropologia da USP, São Paulo, 1959.

CASCUDO, L. D. C. Dicionário do folclore brasileiro. São Paulo: Global, 2012.

DOOLEY, R. A. Léxico Guarani, dialeto Mbyá: com informações úteis para o ensino médio, a aprendizagem e a pesquisa linguística. Anápolis: Associação Internacional de Linguística - SIL Brasil, 2013.

KANGUÁ, V.; POTY, P. M. A vida do sol na terra - Kuaray'i ywy rupáre oiko'i ague. São Paulo: Anhembi Morumbi, 2003.

LADEIRA, M. I. O caminhar sob a luz: o território Mbya à beira do oceano. São Paulo: Pontifícia Universidade Católica - PUC, 2007. Disponivel em:

$<$ http://www.trabalhoindigenista.org.br/noticia/dispon\%C3\%ADvel-na-bd-o-caminharsob-luz-o-territ\%C3\%B3rio-mbya-\%C3\%A0-beira-do-oceano>. Acesso em: 26 Jul 2015. Dissertação de Mestrado em Antropologia. 
LADEIRA, M. I. População > Guarani Mbya. Povos indígenas no Brasil, 2009. Disponivel em: <http://pib.socioambiental.org/pt/povo/guarani-mbya/1289>. Acesso em: 20 nov. 2015.

LORENZONI, C. A. C. D. A. Cestaria guarani do Espírito Santo numa perspectiva etnomatemática. Vitória: Universidade Federal do Espírito Santo, Centro de Educação, 2010.

MARELLI, A. A. Herramientas para comprender el arte Mbyá-Guaraní. Granada: Editorial de la Universidad de Granada, 2011. Disponivel em: <http://hera.ugr.es/tesisugr/20425624.pdf>. Acesso em: 12 Mar 2016.

NOGUEIRA, J. F. S. Etnodesign: um estudo do grafismo das cestarias dos M'byá guarani de Paraty-Mirim. Rio de Janeiro: PUC-Rio, 2005.

PIERRI, D. C. O perecível e o imperecível: lógica do sensível e corporalidade no pensamento guarani-mbya. São Paulo: [s.n.], 2013. Dissertação apresentada ao Programa de Pós-Graduação em Antropologia Social, do Departamento de Antropologia da Faculdade de Filosofia, Letras e Ciências Humanas da Universidade de São Paulo.

SCHADEN, E. Aspectos fundamentais da cultura Guarani. São Paulo: Ed. da Universidade de São Paulo, 1974.

SILVA, A. D. 0 grafismo e o significado do artesanato da comunidade guarani da linha gengibre (desenhos na cestaria). Florianópolis: UFSC, Centro de Filosifia e Ciências Humanas, 2015. Trabalho de Conclusão de Curso.

ZOCCOLI, U. S.; CASTANHEIRA, N. P. O ritual do Kaá dos Mbyá-Guaraini da aldeia Araçaí de Piraquara-PR. Revista Intersaberes, 7, n. 14, Ago - Dez 2012. 30-45. 